\title{
Cough Syrup Psychosis
}

\author{
Alfred Amaladoss, MBChB*; Simon O'Brien, MD, FRCPC ${ }^{*}$
}

\section{ABSTRACT}

Over-the-counter medications are widely accessible and used. Cough suppressant syrups contain dextromethorphan (DM), which has the potential to be abused, with resultant psychiatric symptoms. This case report describes a young woman presenting with psychotic mania secondary to DM abuse. We also describe the treatment of this toxidrome and include the results of a literature search on this topic. The recognition of cough syrup as an agent of abuse and its toxidrome is important. This will facilitate early diagnostic clarification and promote efficient treatment strategies.

\section{RÉSUMÉ}

Les médicaments en vente libre sont facilement accessibles et largement utilisés. Les sirops antitussifs contiennent du dextrométhorphane (DM), qui peut faire l'objet d'un usage excessif pouvant provoquer des réactions psychiatriques. Nous présentons le cas d'une jeune femme à l'urgence présentant des épisodes de manie secondaires à l'usage excessif de DM. Nous décrivons le traitement de ce toxidrome et présentons les résultats d'une recherche documentaire sur le sujet. Il apparaît important de reconnaître l'abus d'antitussifs et son toxidrome, ce qui peut faciliter une clarification précoce du diagnostic et favoriser une prise en charge efficace.

Keywords: cough syrup, dextromethorphan, psychosis, substance abuse

Dextromethorphan (DM) is generally considered to be a safe and nonaddicting drug by laypersons and physicians. ${ }^{1} \mathrm{DM}$ is a synthetic opioid and is an effective over-the-counter (OTC) cough suppressant when taken at the indicated doses. ${ }^{2}$ It is available in over 140 preparations. $^{2}$ Many practitioners consider DM to be an effective short-term cough remedy and continue to recommend its short-term use. ${ }^{3}$ When taken in excess, however, it may lead to both physical and psychiatric manifestations. To recognize this toxidrome and its psychiatric manifestations, we describe the case of a patient presenting with a first episode of mania and psychosis secondary to probable DM use.

\section{CASE REPORT}

A 20-year-old female was brought by the police to the hospital, after making multiple complaints to 911 . When she was interviewed in the emergency department (ED), she reported that the 911 calls she made were fictional. She described bizarre somatic delusions and stated that the medical doctor had injected "Salium" into her anus until it shocked her. She described the "procedure" as lasting 20 minutes. She was paranoid and mentioned that "someone was draining her bank account." She also described experiencing "blacking outs and imagining things"; however, she did not elaborate further on this. Her history was disorganized in the timeline of events; however, she stated that for about 3 weeks, she had experienced increasing "sore throat." She reported using frequent amounts of cough syrup to relieve her sore throat and to aid her sleep. She denied using alcohol or any recreational drugs during this period. There is no reported history of substance abuse.

On review of her chart, it was noted that she had visited the ED on 5 consecutive days, with concerns of worsening sore throat, just 2 days before this admission. On her initial visit to the ED, she was diagnosed with pharyngitis. She was prescribed oxycodone and acetaminophen $5 \mathrm{mg} / 325 \mathrm{mg}$ for symptomatic relief. She was started on clindamycin on her second visit. She had negative Monospot testing and group A streptococcus cultures. It was noted on her third visit that she had some lability. Computed tomography (CT) of the neck

From the *Department of Psychiatry, Queen's University, Kingston, ON.

Correspondence to: Dr. Alfred Amaladoss, Department of Psychiatry, Queen's University, Kingston, ON, K7L5G2; alfiamaladoss@yahoo. ca.

This article has been peer reviewed.

(c) Canadian Association of Emergency Physicians 
performed on her third visit ruled out a retropharyngeal abscess. Otolaryngology was consulted on her third visit with concerns of ongoing sore throat and fever. They assessed her as having a viral stomatitis. Nevertheless, she was discharged with follow-up.

The patient was physically examined, and blood was taken on all ED visits. She was noted to have a mild leukocytosis and raised C-reactive protein on blood work on most visits. She had a normal liver function as assessed by blood work on her initial ED visit. On her last ED visit a day before her admission, Internal Medicine was consulted. The assessment, once again, was benign, and she was later discharged. There was no report of any psychiatric symptoms apart from lability, which was noted on her third ED visit. On all ED visits, she was treated symptomatically with morphine and ketorolac in the ED to mitigate the pain she was experiencing as a result of her sore throat. There was no report of any substance withdrawal on any of her visits.

On review, her past psychiatric history showed no previous hospitalizations. There was a remote note of her suffering from "minor depression and adjustment stress" in the past that was uncomplicated, without any admission. Her medications included trazodone $50 \mathrm{mg}$ hs PO and temazepam $15 \mathrm{mg}$ hs PO, which she took as prescribed on an as-needed basis for mild insomnia. Her family history was not significant for any mental illness. Medically, she was healthy apart from a diagnosis of fibromyalgia since the age of 16 years. There were no known allergies.

\section{TREATMENT COURSE AND OUTCOME}

Following the patient's history and presentation, a physical examination was performed by the ED team before Psychiatry was consulted. She was medically cleared, with no report of any focal neurologic findings. Her vitals on admission were as follows: blood pressure of $106 / 67 \mathrm{~mm} \mathrm{Hg}$, heart rate of 74 beats/min, respiratory rate of 16 breaths $/ \mathrm{min}$, saturation of $98 \%$ at room air, and temperature of $36.2^{\circ} \mathrm{C}$. Her blood work showed a mild leukocytosis of $12.9 \times 10^{9}$ cells $/ \mathrm{L}$ and a normal hemoglobin and platelet count. Her sodium was $142 \mathrm{mmol} / \mathrm{L}$, potassium was $3.4 \mathrm{mmol} / \mathrm{L}$, creatinine was $81 \mu \mathrm{mol} / \mathrm{L}$, and urea was $5.1 \mathrm{mmol} / \mathrm{L}$, and she had a normal calcium level. Her urine toxicology screen was positive for opiates, acetaminophen, benzodiazepines, and tricyclic antidepressants. Her serum blood alcohol level and urine pregnancy test were negative. CT of her head was not performed; however, it would have been considered if she was delirious or had any focal neurologic deficits at the time of presentation.

At her mental status examination, she was appropriately groomed, with good eye contact. She was talkative, and her speech was pressured. She described her mood as "good," and her affect was labile. She had delusional thoughts of the somatic and paranoid type. Her thought process was circumstantial, with occasional tangentiality. She described dissociative perceptual changes. Cognitively, she was awake and alert and not delirious. She was admitted as an inpatient to the psychiatry ward with the provisional diagnosis of substance-induced psychosis.

Over the course of 4 days of hospitalization in the psychiatric unit, she improved with a total of four doses of olanzapine given at $5 \mathrm{mg}$ PO once daily. Her manic symptoms, together with the accompanying psychosis, completely resolved, and she was discharged after having spent 4 days in hospital. She is currently followed as an outpatient. She is stable, with no relapse episodes of mania or psychosis, and is currently functioning well in postsecondary training. She is not on olanzapine currently. In retrospect, when questioned regarding this episode, she reported taking "frequent tablespoons of cough syrup a day." She was uncertain about any details of the episode and could not clarify the cough syrup brand. She denied any history of seizures or any previous head injuries in the past.

\section{DISCUSSION}

This case required consideration of important and potential diagnoses that would explain the patient's behaviour. These included substance-induced mood disorder (particularly hallucinogen induced), delirium, mania secondary to a generalized medical condition, primary bipolar mood disorder in the manic phase, and other DSM-IV psychotic disorders. Our patient was assessed on five consecutive days in the same ED with both physical examination and biochemical testing on 5 consecutive days in the ED. The concerns documented during the visits were primarily around ongoing sore throat only with no mention of other medical issues or complications.

This case highlights the importance of considering and recognizing that even common OTC medications 
such as cough syrup used for symptom relief can be abused and result in psychiatric manifestations. The intoxication effects of DM are varied based on multireceptor triggering. Symptoms range from euphoria, a sense of well-being, slurred speech, ataxia, dissociation, nystagmus, and psychosis. ${ }^{2}$ Other symptoms include impaired muscle tone, hyperexcitability, dissociative anesthesia, depersonalization, out-of-the-body dream state, and agitation. ${ }^{4}$ These can be explained through $N$-methyl-D-aspartate (NMDA) ${ }^{5}$ antagonism, sigmoid opioidergic agonism, ${ }^{6-8}$ and serotonin enhancement. ${ }^{9}$ The effects of DM are similar to those of ketamine and phencyclidine (PCP). ${ }^{4}$

Schadel and Sellers first suggested that DM could be the causative agent with earlier reports of psychosis following excessive cough syrup ingestion. ${ }^{10} \mathrm{DM}$ is converted to dextrorphan (DOR). DM and DOR are classified as dissociatives and have properties consistent with NMDA receptor antagonists such as PCP and ketamine. ${ }^{2}$ Most cough syrups contain 10 to $15 \mathrm{mg}$ of DM per teaspoon $(5 \mathrm{~mL}){ }^{2}$ There is little or no psychological effect associated with ingestion of the recommended doses for DM antitussive therapy (10 $30 \mathrm{mg}){ }^{3}$ With regard to dose and effect, over $4 \mathrm{oz}$ of $\mathrm{DM}$ is required for dissociative symptoms. ${ }^{2}$ As little as $2 \mathrm{oz}$ will generally produce euphoria and distort perceptions. Four ounces will produce extreme intoxication, which includes hallucinations and psychosis. ${ }^{11}$ Schadel and Sellers described psychosis in doses greater than $600 \mathrm{mg}$ of $\mathrm{DM}^{10} ; 8$ to $10 \mathrm{oz}$ will produce complete dissociation and out-of-body dissociative experiences. ${ }^{11}$ The above information raised the possibility of DM as the offending agent in our patient, as evidenced by her psychiatric symptoms, namely lability, delusions, and dissociative features. Our patient also reported to have taken several tablespoons of cough syrup per day; 1 tablespoon is equivalent to $15 \mathrm{~mL}$. Therefore, her total daily dose of DM prior to admission was equivalent to approximately $45 \mathrm{mg}$, which exceeded the recommended dose, as indicated above. Also, the quantity (several tablespoons per day) indicated by the patient would be in the range to explain the possible psychiatric symptoms described in this case. This is likely as doses of DM taken 5 to 10 times the therapeutic dose may include effects similar to those of ketamine and PCP. ${ }^{4}$

The presence of benzodiazepines and tricyclic antidepressants is better explained through the symptomatic treatment the patient received for her insomnia. Acetaminophen present in the urine reflected the treatment of oxycodone and acetaminophen that was prescribed by the ED team for symptomatic pain relief since her first ED visit. The presence of opiates in our case may be explained through the morphine received on serial visits to the ED and possibly from her cough syrup ingestion. Doses of 15 to $30 \mathrm{mg}$ of DM will not produce falsepositive tests for opiates; however, large doses of DM have reportedly caused a false-positive test for PCP or opiates. ${ }^{4}$ From the above-mentioned DM doses, it is possible that our patient may have taken more than $30 \mathrm{mg}$ per day. This is suspected based on her clinical features (which are noted in high doses) and would also explain the possible presence of opiates in her urine. Early detection of DM, however, has not been available in Canada because it is not routinely assayed in urine toxicology screening. ${ }^{12}$ Nevertheless, all positive screening tests for PCP should be confirmed with gas chromatography/mass spectrometry in light of a possible false-positive test for PCP with highdose DM. ${ }^{4}$ This should be a consideration for clinicians faced with the above dilemma.

Our case also documents the efficacy of treatment of DM intoxication with four doses of olanzapine at $5 \mathrm{mg}$. The dramatic improvement in her psychosis over a short period on treatment alerted us to possible substance-induced psychosis. Repeat ED visits for the same problem should alert ED physicians to the possibility of disease progression, misdiagnosis, or complications of treatment.

This presentation met the probable findings of DM intoxication as follows: (1) the knowledge of our patient's increased consumption of cough syrup containing DM, which was noted to be above the required and recommended therapeutic dosage; (2) consecutive medical assessment over 5 days prior to her presentation, with no medical or psychiatric complications noted; she presented on the last visit to the ED with an acute change in her mental status that led to her admission; (3) the change in her mental status, as evident in her psychiatric symptoms, could be better explained by probable DM intoxication than the other medications she was prescribed; (4) the dramatic improvement in mental status when treated with an antipsychotic raised the possibility of substanceinduced psychosis, particularly with the stability in functioning after discharge from hospital even after she was no longer receiving olanzapine treatment. 
This case report describes the presentation of probable DM intoxication and successful treatment. With the overwhelming availability of OTC medication, cough syrups in particular, all clinicians need to diligently ask patients about OTC abuse. Cough syrup psychotic mania should be recognized early and supportive treatment provided in those giving a history of or suspected of having DM intoxication.

Competing interests: None declared.

\section{REFERENCES}

1. Bem JL, Peck R. Dextromethorphan. An overview of safety issues. Drug Saf 1992;3:190-9.

2. Miller SC. Dextromethorphan psychosis, dependence and physical withdrawal. Addict Biol 2005;10:325-7.

3. The Vaults of Erowid. Available at: http://www.erowid.org/ (accessed October, 2010).

4. Swartz RH. Adolescent abuse of dextromethorphan. Clin Pediatr (Phila) 2005;45:565-8.

5. Franklin $\mathrm{PH}$, Murray TF. High affinity $\left[\mathrm{H}^{3}\right]$ dextrorphan binding in rat brain is localized to a noncompetitive antagonist site of the activated N-methyl-D-aspartate receptor-cation channel. Mol Pharmacol 1992;41:134-46.

6. Whittemore ER, Ilyin VI, Woodward RM. Antagonism of N-methyl-D-aspartate receptors by [sigma] site ligands: potency, subtype-selectively and mechanism of inhibition. 7 Pharmacol Exp Ther 1997;282:326-38.

7. Gonzalez GM, Werling LL. Release of $\left[{ }^{3} \mathrm{H}\right]$ dopamine from guinea pig striatal slices is modulated by sigma 1 receptor agonists. Naunyn Scmiedebergs Arch Pharmacol 1997;356:455-61.

8. Yamamoto H, Yamamoto T, Sagi N, et al. Sigma ligands indirectly modulate the NMDA receptor-ion channel complex on intact neuronal cells via sigma 1 site. $f$ Neurosci 1995;15:731-6.

9. Meoni P, Tortella FC, Bowery NG. An autoradiographic study of dextromethorphan high-affinity binding sites in rat brain: sodium-dependency and colocalization with paroxetine. Br 7 Pharmacol 1997;120:1255-62.

10. Schadel M, Sellers E. Psychosis with Vicks Formula 44D. Can Med Assoc 7 1992;147:843-4.

11. Dickerson DL, Schaepper MA, Peterson MD, et al. Coricidin HBP abuse: patient characteristics and psychiatric manifestations as recorded in an inpatient psychiatric unit. $\mathcal{f}$ Addict Dis 2008;1:25-32.

12. Price LH, Lebel J. Dextromethorphan-induced psychosis. Am 7 Psychiatry 2000;157:304. 